\title{
Effect of Autologous Fibrin Glue on Seroma Reduction after Modified Radical Mastectomy for Breast Cancer: A Randomized Controlled Trial
}

\author{
Mohammed Faisal ( $\nabla$ m.faisal@med.suez.edu.eg )

\section{Sara Salem} \\ Suez Canal University Faculty of Medicine \\ Noha Kamel \\ Suez Canal University Faculty of Medicine \\ Haidi Abd El Zaher \\ Suez Canal University Faculty of Medicine

\section{Ahmed Abo Bakr} \\ Suez Canal University Faculty of Medicine \\ Hamada Fathy \\ Suez Canal University Faculty of Medicine
}

Suez Canal University Faculty of Medicine https://orcid.org/0000-0002-2162-1741

\section{Research}

Keywords: breast cancer, seroma, fibrin glue, autologous

Posted Date: October 2nd, 2020

DOI: https://doi.org/10.21203/rs.3.rs-84034/v1

License: (c) (i) This work is licensed under a Creative Commons Attribution 4.0 International License. Read Full License

Version of Record: A version of this preprint was published at Annals of Medicine and Surgery on March 1 st, 2021. See the published version at https://doi.org/10.1016/j.amsu.2021.01.083. 


\section{Abstract}

Introduction Breast cancer stands out as the second most common cancer in the world with incidence $35.1 \%$ of all malignancies among females in Egypt. Fluid build-up after breast surgery is still the most annoying complication which leads to worse outcome. We aimed to evaluate whether autologous fibrin glue might lessen the formation of seroma following modified radical mastectomy.

Methods This was a randomized controlled trial designed to configure the effect of autologous fibrin glue given in the study group using the drain in comparison to a control group who received the drain only; seroma volume was calculated every $24 \mathrm{hrs}$. For all of the cases. The drains were removed when the daily drainage was less than $30 \mathrm{ml}$ for 3 consecutive days.

Results We recruited 30 patients to each of the two groups. Age, pathology, breast cancer stage, number of lymph nodes and tumour size did not differ significantly between groups. A comparison of the median days to drain removal showed 8 days reduction in median days to drain removal compared in the intervention group (7 days) than the control (15 days). The patients in the fibrin glue group had a significantly lower cumulative drain output volume (mean \pm SD of $505.6 \pm 209.3 \mathrm{ml}$ ) than those in the control group $(1674.1 \pm 1373.8 \mathrm{ml}$ ). Additionally, the patients treated with fibrin glue had a significantly shorter postoperative length of stay (8.5 (7-10) days) than the controls (15 (10-23) days.

Conclusions Autologous fibrin glue significantly decrease seroma formation post-modified radical mastectomy. Research Registry Unique Identifying Number: researchregistry5372.

\section{Introduction}

Breast cancer stands out as the second most common cancer in the world and is the commonest in women. The distribution varies significantly between continents from 27 in 100,000 in Central Africa and Eastern Asia to 96 per 100,000 in Western Europe [1].

Seroma is a very popular and annoying problem post breast and lymph nodes removal leading to the majority of complications that happens, for instance, wound infection, skin flap necrosis, wound dehiscence, nerve injuries and lymphedema. Because of the potentially severe effects of seroma, several approaches have been described to obliterate the dead space aiming at reduction of seroma formation; for example, using compression bandage, suction drains, flap fixation with sutures, utilization of ultrasound scalpel or laser scalpel in dissection, sclerotherapy, immobilization from the affected arm, topical use of tranexamic acid and fibrin glue application [2-5].

Fibrin glue, light-activated fibrin sealant, and transdermal photopolymerized adhesive have been associated with reduction in the fluid build-up post mastectomy through various studies [6-9]. Fibrin glue acts by lessening the number of disrupted lymphatics and minute vessels during axillary dissection hence resulting in lowering of seroma output $[6,10]$ and provide hemostasis by controlling the hematomas which may delay wound healing. In addition, the fibrin glue has been recommended to interfere with the broken tissues during surgery, promoting the emergence of fibroblasts so enhancing closure of the wound through blockage of the dead spaces by tissue adhesion [5, 11].

However, conflicting results have been reported regarding whether the fibrin glue plays a role in lowering the generation of seroma after breast cancer surgery or not [12-14]. 
Therefore, we aimed to reduce seroma formation after modified radical mastectomy (MRM) by using autologous fibrin glue, which has the advantage of being safe and inexpensive.

\section{Methods}

This research was a randomized controlled trial that was carried out at the surgery departments of Suez Canal college Hospital from July 2017 to December 2018. The study was reviewed by our research ethics committee in the Faculty of Medicine of Suez Canal University at its meeting on 11/6/2017. The study adhered to CONSORT guideline.

\section{Patients}

In the current work, sixty consecutive patients who were diagnosed with breast cancer and treated by MRM were recruited.

Newly diagnosed breast cancer stage I or II, who had no previous surgery on the axillary lymphatic system on the same side, no previous radiotherapy, nor corticosteroid treatment were included (Flow chart).

\section{Autologous Fibrin Glue preparation}

The fibrin glue was prepared at Suez Canal University Hospital blood bank. All recruited patients were eligible for autologous blood donation. Three days prior to surgery, approximately $450 \mathrm{~mL}$ were obtained in triple blood bags containing $70 \mathrm{~mL}$ CPDA-1 (purchased from JMS, Singapore). The plasma was separated from the red blood cells within 2 hours by centrifugation (Centrifuge: Thermo Sorvall ${ }^{\mathrm{TM}}$ RC 12BP, Thermo Fisher Scientific, USA) at $2200 \times \mathrm{g}$ for 10 minutes. The plasma was frozen and stored for 48 hours at $-40^{\circ} \mathrm{C}$. Then, fresh frozen plasma was thawed at $4^{\circ} \mathrm{C}$ for 8 hours before centrifugation at $2200 \times \mathrm{g}$ for 10 minutes and the supernatant plasma was transported to the other satellite bag. The cryoprecipitate was suspended in $15 \mathrm{ml}$ of plasma. Seven millilitres of fibrinogen and factor XIII (which is a fibrin stabilizing factor) containing precipitate were drawn into a syringe.

An hour before the operation. We used autologous thrombin obtained by drawing $14 \mathrm{ml}$ of blood from the patient in plain tubes, which were left 30 minutes until clotting occurred and then centrifuged at $1000 \times g$ for 12 minutes; then the supernatant was collected (About $7 \mathrm{ml}$ ), which represents autologous thrombin [15]. Then, we added the cryoprecipitate in equal volume to the thrombin. Finally, we added $2 \mathrm{ml}$ calcium gluconate $(50 \mathrm{mg} / \mathrm{mL}$ calcium gluconate monohydrate) just before 2 minutes of application into the flaps.

\section{Randomization}

The patients were randomly allocated to either the intervention or control group. Once the patient consented to enter the trial, each patient was randomly assigned using sealed white envelopes. Patients were equally allocated at a ratio of 1:1 to either the intervention or control group.

\section{Intervention}

All patients underwent MRM. The same technique was followed in both groups; the use of electrocautery was minimized as much as possible, and meticulous haemostasis was performed. After mastectomy, the intervention cases received fibrin glue plus drain insertion before wound closure. The prepared glue mixture was sprayed after the field had dried completely; $8 \mathrm{ml}$ were applied to the dead space under the skin flaps, and the other $8 \mathrm{ml}$ were applied to the axillary bed. (Fig. 1) 
After spraying the mixture, we exerted gentle pressure for at least 5 minutes over the flaps and axilla and then closed the wound in layers as rapidly as possible. Last, we placed a small compressing cotton pad in the axilla. In the control group, we performed MRM using the same technique with meticulous haemostasis but closed the flaps immediately after inserting the drains (In both groups, we inserted two separate suction drains one at the axilla, and the other under skin flaps).

In both groups, we removed the drains once the volume of drained fluid was less than or equal to $30 \mathrm{~cm} 3$ per day, for 3 successive days.

\section{Outcome measures}

The major factor assessed in the trial was the amount of drained fluid in the postoperative period; the secondary outcome was the duration took to remove the drain. In addition, we recorded the number of excised lymph nodes and the pathology results.

\section{Statistical analysis}

The gathered information were examined using IBM Statistical Package for Social Sciences software (SPSS), 21st edition. Continuous data were expressed as mean \pm standard deviation and categorical data as frequencies and percentages. When data were tested for normality, they were not normally distributed, therefore, Mann Whiney $U$ test and Kruskal Wallis test were used to compare continuous variables between different groups. Fisher's exact test and chi-square test were used for statistical analysis of categorical variables. Time-to-drain removal was analysed with survival analysis. Survival function was presented as Kaplan Meier curve, while the log rank test was used to test for the statistical significance of the difference in survival distribution between the intervention group and its control. For all tests a probability value of less than 0.05 was considered statistically significant.

\section{Result}

Sixty Patients were enrolled and at random assigned to either the intervention $(n=30)$ or control group $(n=30)$. Their baseline characteristics (age, pathology type, and tumor stage and breast weight) are represented in Table 1 . The mean age was $53 \pm 4.7$ years in the control group and $50 \pm 3.7$ years in the intervention group, without any significant record distinction among the particular groups. The majority of the patients had invasive ductal carcinoma (93.3\%); 2 had stage I lesions, and 58 had stage II lesions (Table 1).

The entire amount of seroma formation in the group who received fibrin glue was $505.6 \pm 209.3 \mathrm{ml}$, while in the control group it was $1674.1 \pm 1373.8 \mathrm{ml}(p<0.001)$ (Table 2).

A comparison of the hospital stay length between the studied cases showed that the patients who were treated using fibrin glue after surgery had a significantly shorter hospital stay (8.5 (range 7-10) days) than those who were not treated using fibrin glue (15 (10-23) days) $(p=0.01)$ (Table 2$)$.

The usage of fibrin glue after mastectomy and axillary clearance showed 8 days reduction in median days to drain removal compared with the group who did not use fibrin glue (log-rank p-value =0.01) (Fig. 2).

Many factors other than fibrin glue can affect total volume of fluid build-up such as amount of excised lymph nodes, tumour size and breast weight, in the present study we found non-significant difference between patients from both groups regarding those factors. 
In this study we found that higher number of excised lymph nodes were associated with significantly more seroma volume $(p<0.001)$. On applying post hoc test, it was found that patients with more than 25 excised lymph nodes had significantly more seroma volume than all other groups $(p<0.001)$, and patients with 15-25 excised lymph nodes had significantly more seroma volume than those with less than 15 excised lymph nodes $(p<0.001)$ (Fig. 3).

Additionally, higher tumour size was associated with significantly more seroma volume $(p<0.001)$. On applying post hoc test, it was found that cases with tumour size $>5 \mathrm{~cm}$ had significantly more seroma volume than tumour size 3$5 \mathrm{~cm}$ and $\leq 3 \mathrm{~cm}(p<0.001)$, and patients with tumour size $3-5 \mathrm{~cm}$ had significantly more seroma volume than those with tumour size $\leq 3 \mathrm{~cm}(p<0.001)$ (Table 2).

Moreover, patients with breast size of more than 1000 to less than $3000 \mathrm{gm}$ and those with breast size more than $3000 \mathrm{gm}$ had significantly more seroma volume than those with size between $500-1000 \mathrm{gm}(p<0.001)($ Table 2$)$.

\section{Discussion}

A documented method for seroma reduction post breast excision has not yet been established. So, we aimed to reduce seroma formation by safe, cheap and easily brought method through applying autologous fibrin glue.

In the present study, we found a significant decrease in the total volume of aspirated fluid in the group who received fibrin glue compared to the control. This finding is in accordance with the results documented by other authors who used commercial fibrin glue in their interventions [5, 7-9].

However, conflicting results were found by other authors, who reported inconclusive results or even harmful effects of fibrin glue which were explained by the presence of drains that may interfere with the maturation of the fibrin clot and the blockage of the lymphatic vessels [16-18]. However, there are important variations between those studies and ours. Cha and his colleagues applied fibrin glue following a different surgical treatment, an instantaneous breast renovation employing a latissimus dorsi myocutaneous flap [13]. While, Burak and co-authors [12] used only bovine thrombin which constitutes one element of fibrin glue, which might explain why they were unsuccessful to acquire a significant outcome, and similar outcome was reported by Cipolla and colleagues [6] in their study. Using fibrin glue in a low or unsuitable concentration, using bovine thrombin and fibrinogen, or using only one of these two components might reduce the effectiveness of fibrin glue. Therefore, we opted to utilize autologous fibrinogen and thrombin in our fibrin glue preparation. Additionally, we closed the wound rapidly after the fibrin glue was applied because it appears to be really vital that you take the most from the sealing effect and adhesive strength from the glue. When the wound is quickly closed after using glue, the wound surfaces can effectively bond with the glue polymerization period, however, if there's a delay, polymerization within the glue can happen before tissue adherence is completed.The polymerized glue may hinder rather than allowing adhesion effectively, being a barrier between opposing tissue surfaces $[10,19]$. In the present study, we took great care to avoid this condition by mildly compressing the wounds immediately after spraying the fibrin glue for at least 5 minutes, and then closing the wounds as rapidly as possible.

Using fibrin glue reduced the drainage duration in breast cancer patients undergoing level II or III axillary dissection [20]. In contrast, a study by Ulusoy and co-authors [18] found no obvious change in the daily output, drain removal time, seroma formation frequency between the two groups.

Regarding the factors associated with the volume of the aspirated seroma, we found that lower preoperative breast weight, lower tumour stage, lesser number of excised lymph nodes, and smaller tumour size were all associated with smaller amounts of aspirated fluid. This agrees with a previous study [17] but is contrary to what was reported by

Page 5/14 
other studies who found that tumour size and location, histological type, disease site and specimen weight were not associated with increased seroma formation [21, 22].

Finally, the utilization of fibrin glue led to a median of 8 days reduction in the time required to drain removal. This can be explained by the effectiveness of autologous fibrin glue in lessening the amount of seroma, and therefore reducing the period needed to drain removal.

To our knowledge, the current research represents the first work to use fibrin glue from autologous nature to reduce seroma formation after Modified Radical Mastectomy for breast cancer as a randomized clinical intervention, which makes our finding unique even though they are borderline significant.

The limitations of this study include small sample size, and short follow up duration. All the patients treated with autologous fibrin glue had no seroma collected after drain removal in opposite to what happened with most of the control group; however, we did not follow up for longer period after drain removal.

\section{Conclusion}

The present study supports the utilization of autologous fibrin glue in order to lessen post-modified radical mastectomy seroma. Further larger prospective studies and follow up for longer period after drain removal are recommended.

\section{Declarations}

\section{Ethical approval and consent to participate:}

All procedures performed in our study involving human participants was in accordance with the ethical standards of the institutional and/or national research committee and with the 1964 Helsinki declaration and its later amendments or comparable ethical standards. This research has been reviewed by our research ethics committee in the Faculty of Medicine of Suez Canal University at its meeting on 11/6/2017 with reference number 3311\#. Written and verbal informed consent was obtained from the selected patients.

\section{Availability of data and materials}

The datasets used and/or analysed during the current study are available from the corresponding author on reasonable request.

\section{Consent for publication}

We have received consent for all cases reported in our study according to an institutional consent form.

Competing interest: The authors declare no competing interest.

Funding: No funding resources.

\section{Acknowledgment}

Special thanks, admiration, and respect to all our department members for their kind help, guidance and valuable support. 


\section{References}

1. Ferlay J, Soerjomataram I, Dikshit R, Eser S, Mathers C, Rebelo M, et al. Cancer incidence and mortality worldwide: Sources, methods and major patterns in GLOBOCAN 2012: Globocan 2012. Int J Cancer. 2015;136:E359-86.

2. Faisal M, Fathy $\mathrm{H}$, Shaban H, Abuelela ST, Marie A, Khaled I. A novel technique of harmonic tissue dissection reduces seroma formation after modified radical mastectomy compared to conventional electrocautery: a single-blind randomized controlled trial. Patient Saf Surg [Internet]. 2018 [cited 2018 Sep 19];12. Available from: https://pssjournal.biomedcentral.com/articles/10.1186/s13037-018-0155-3

3. Faisal M, Abu-Elela ST, Mostafa W, Antar O. Efficacy of axillary exclusion on seroma formation after modified radical mastectomy. World J Surg Oncol [Internet]. 2016 [cited 2018 Sep 19];14. Available from: http://www.wjso.com/content/14/1/39

4. Eldesouky MS, Ashour HSA, Shahin MA. Effect of topical application of tranexamic acid on reduction of wound drainage and seroma formation after mastectomy. :4.

5. Miri R, Rabbani A, Neishaboury M, Kalantar-Moatamedi M, Khazaeipour Z, Kaviani A. Role of Capitonage and Fibrin Sealant in Reducing Seroma Formation after Breast Conservation Surgery: A Randomized Clinical Trial. :6.

6. Cipolla C, Fricano S, Vieni S, Graceffa G, Licari G, Torcivia A, et al. Does the use of fibrin glue prevent seroma formation after axillary lymphadenectomy for breast cancer prospective randomized trial in 159 patients. J Surg Oncol. 2010;101:600-3.

7. Fawzy A, Gaber A, Farid AAM. Role of fibrin glue in seroma reduction after modified radical mastectomy. Int Surg J. 2017;4:2103.

8. Docimo G, Limongelli P, Conzo G, Gili S, Bosco A, Rizzuto A, et al. Axillary lymphadenectomy for breast cancer in elderly patients and fibrin glue. BMC Surg. 2013;13 Suppl 2:S8.

9. Lee JC, Teitelbaum J, Shajan JK, Naram A, Chao J. The effect of fibrin sealant on the prevention of seroma formation after postbariatric abdominoplasty. Can J Plast Surg J Can Chir Plast. 2012;20:178-80.

10. Moore M, Burak WE, Nelson E, Kearney T, Simmons R, Mayers L, et al. Fibrin sealant reduces the duration and amount of fluid drainage after axillary dissection: a randomized prospective clinical trial. J Am Coll Surg. 2001;192:591-9.

11. Sampathraju S, Rodrigues G. Seroma Formation after Mastectomy: Pathogenesis and Prevention. Indian J Surg Oncol. 2010;1:328-33.

12. Burak WE, Goodman PS, Young DC, Farrar WB. Seroma formation following axillary dissection for breast cancer: risk factors and lack of influence of bovine thrombin. J Surg Oncol. 1997;64:27-31.

13. Cha HG, Kang SG, Shin HS, Kang MS, Nam SM. Does fibrin sealant reduce seroma after immediate breast reconstruction utilizing a latissimus dorsi myocutaneous flap? Arch Plast Surg. 2012;39:504-8. 
14. Carless PA, Henry DA. Systematic review and meta-analysis of the use of fibrin sealant to prevent seroma formation after breast cancer surgery. Br J Surg. 2006;93:810-9.

15. Cavichiolo J, Buschle M, Carvalho B. Comparison of fibrin adhesives prepared by 3 different methods. Int Arch Otorhinolaryngol. 2014;17:062-5.

16. Dinsmore RC, Harris JA, Gustafson RJ. Effect of fibrin glue on lymphatic drainage after modified radical mastectomy: a prospective randomized trial. Am Surg. 2000;66:982-5.

17. SB, G. SH, Naidu M, Gopalkrishna V. A study to evaluate the factors influencing seroma formation after breast cancer surgery at tertiary care centre. Int Surg J. 2018;6:278.

18. Ulusoy AN, Polat C, Alvur M, Kandemir B, Bulut F. Effect of fibrin glue on lymphatic drainage and on drain removal time after modified radical mastectomy: a prospective randomized study. Breast J. 2003;9:393-6.

19. Moore MM, Nguyen DH, Spotnitz WD. Fibrin sealant reduces serous drainage and allows for earlier drain removal after axillary dissection: a randomized prospective trial. Am Surg. 1997;63:97-102.

20. Ko E, Han W, Cho J, Lee JW, Kang SY, Jung S-Y, et al. Fibrin glue reduces the duration of lymphatic drainage after lumpectomy and level II or III axillary lymph node dissection for breast cancer: a prospective randomized trial. J Korean Med Sci. 2009;24:92-6.

21. Antonio M, Pietra T, Domenico L, Massimo D, Ignazio R, Antonio N, et al. Does LigaSure reduce fluid drainage in axillary dissection? A randomized prospective clinical trial. Ecancermedicalscience. 2007;1:61.

22. Sakkary MA. The value of mastectomy flap fixation in reducing fluid drainage and seroma formation in breast cancer patients. World J Surg Oncol. 2012;10:8.

\section{Tables}

Table (1) Baseline characteristics of the patients $(n=60)$ 


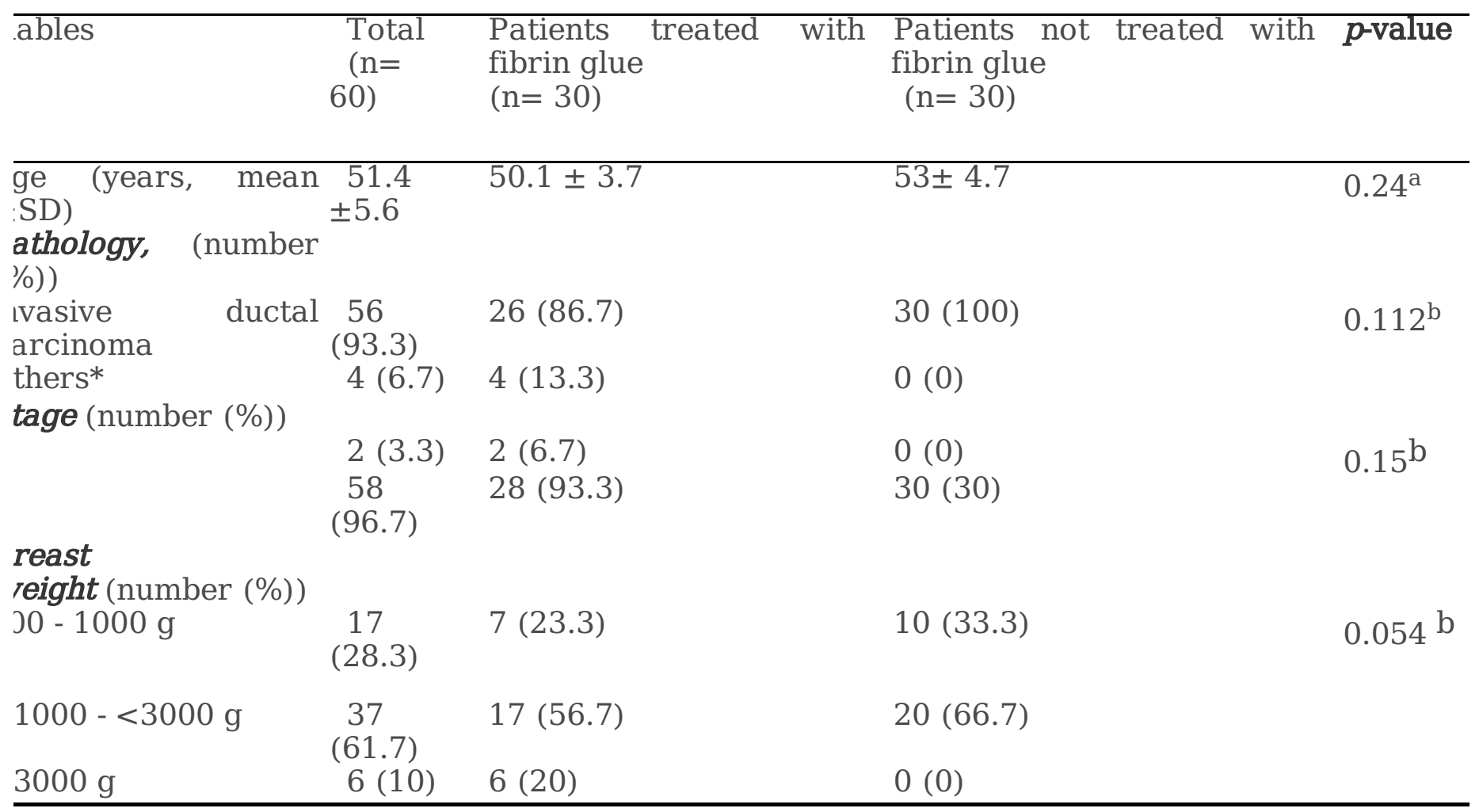

value is based on the Mann-Whitney $\mathrm{U}$ test. Statistical significance at $p<0.05$ values are based on the Fisher exact test. Statistical significance at $p<0.05$ ıers: Invasive lobular carcinoma, Paget's disease of the breast.

Table (2). Comparison of lymph node count, tumor size, volume of aspirated fluid, length of stay (LOS) and in patients treated with and without fibrin glue $(n=60)$ 
Variables

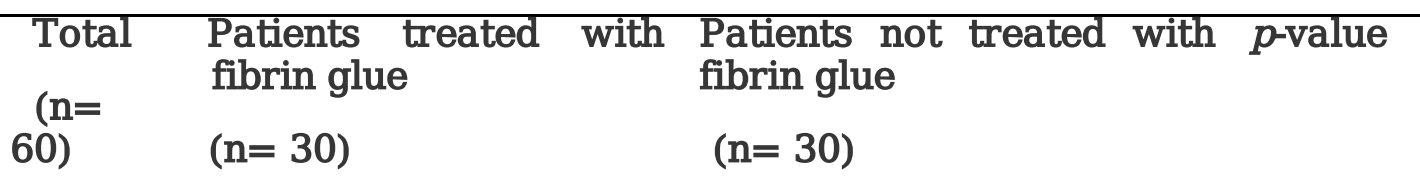

\section{-ymph node count}

$\leq 15$

14
$(23.3)$

7 (23)

7 (23)

$0.191^{\mathrm{a}}$

L5-25

$\begin{array}{cc}34 & 20(66.7) \\ (56.7) & \end{array}$

14 (46.7)

$>25$

12 (20) $10(33.3)$

$2(6.7)$

Гumor size

$=3 \mathrm{~cm}$

18 (30) 10 (33.3)

8 (26.7)

3-5 cm

38

$>5 \mathrm{~cm}$

$4(6.66) \quad 2(6.66)$

$18(60)$

(5)

Cotal volume of aspirated fluid (ml)

Hospital LOS (days)

$505.6 \pm 209.3$

2 (6.66)

$1674.1 \pm 1373.8$

$<0.001^{*}$

${ }^{\text {a }} \mathrm{P}$-values are based on the chi-square test. Statistical significance at $p<0.05$

- P-value is based on the Mann-Whitney U test. Statistical significance at $p<0.05$

\section{Figures}




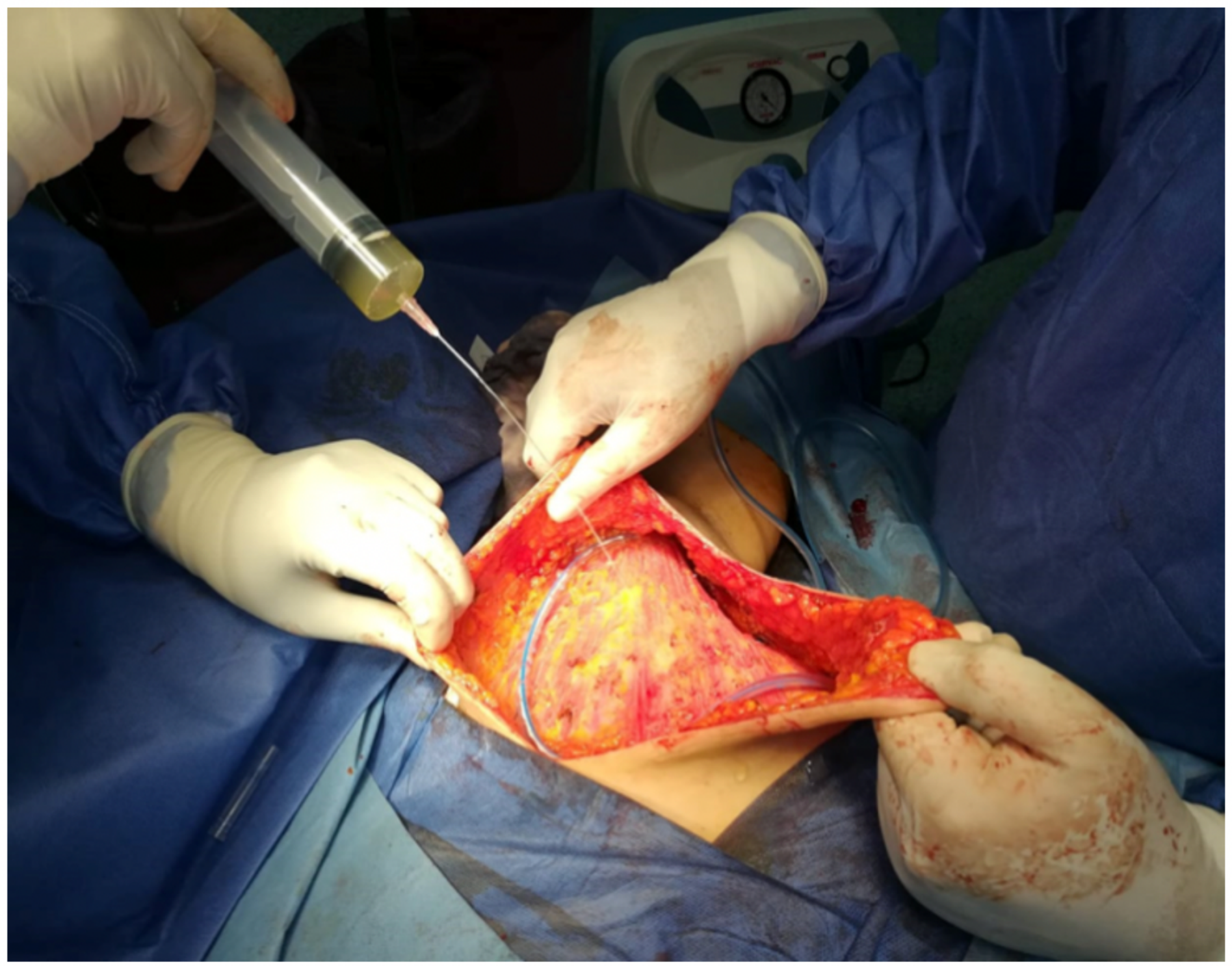

Figure 1

Application of the fibrin glue after MRM. 


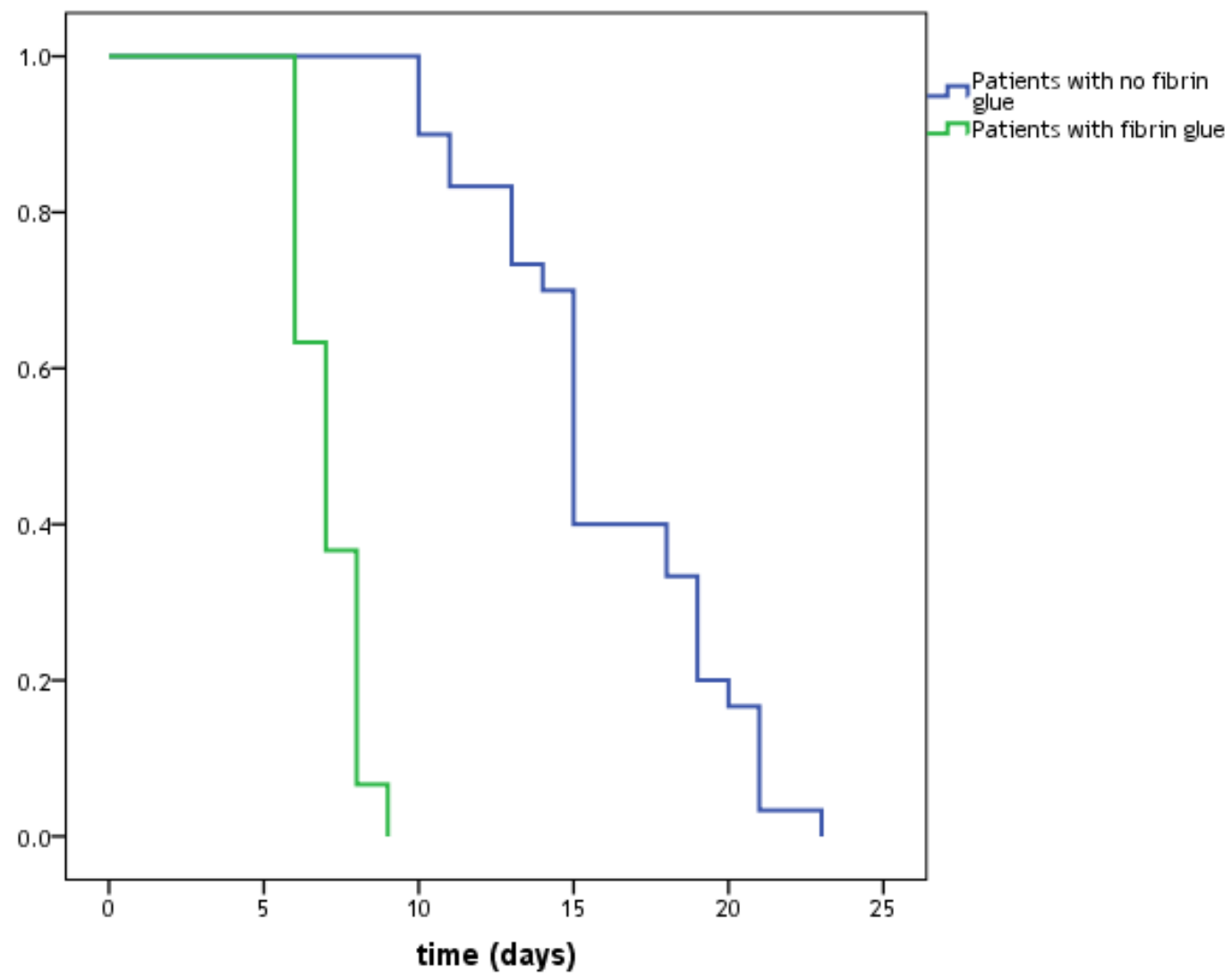

Figure 2

Time to drain removal in modified radical mastectomy patients in both groups. 


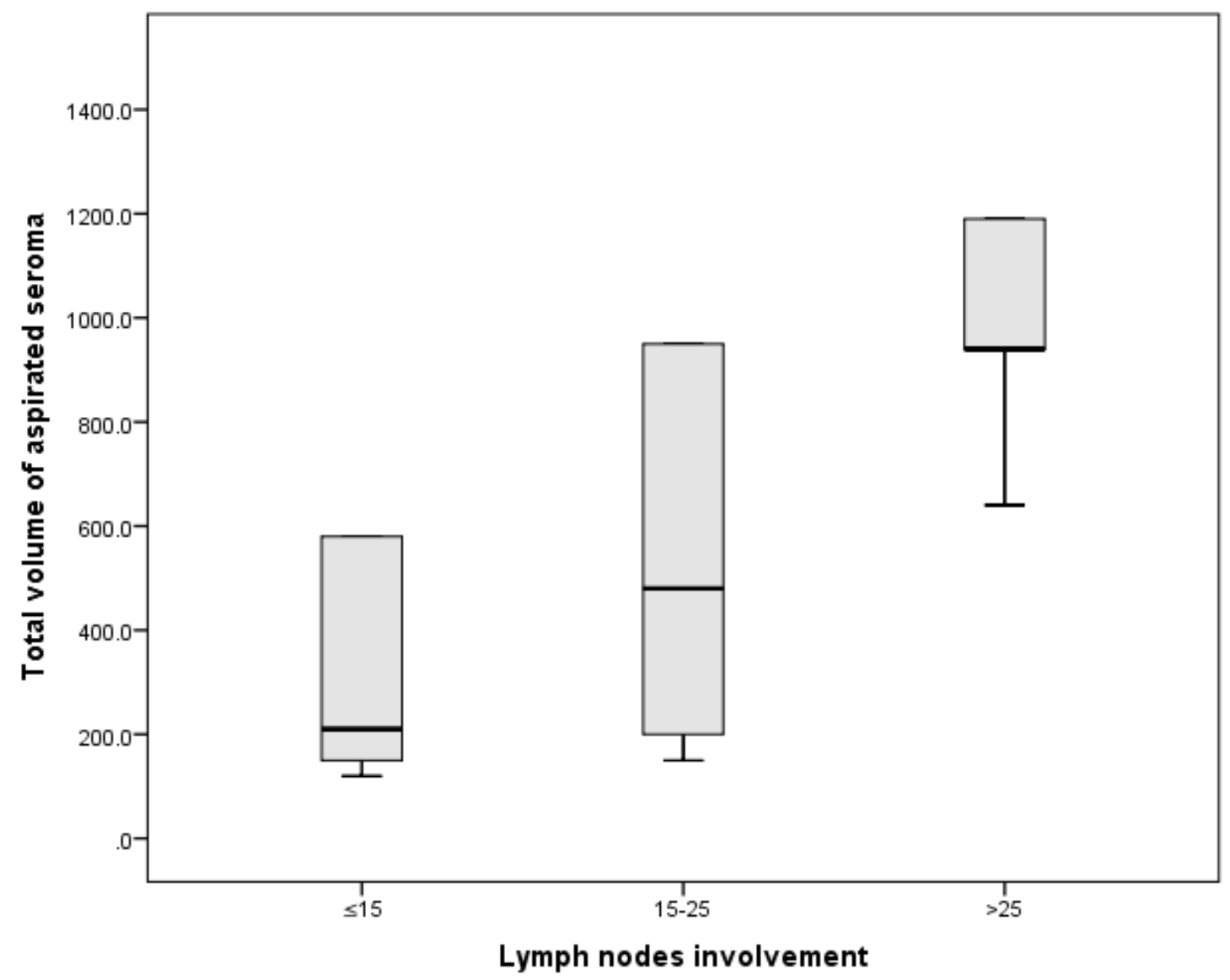

Figure 3

Association between total volume of seroma and lymph nodes involvement. 


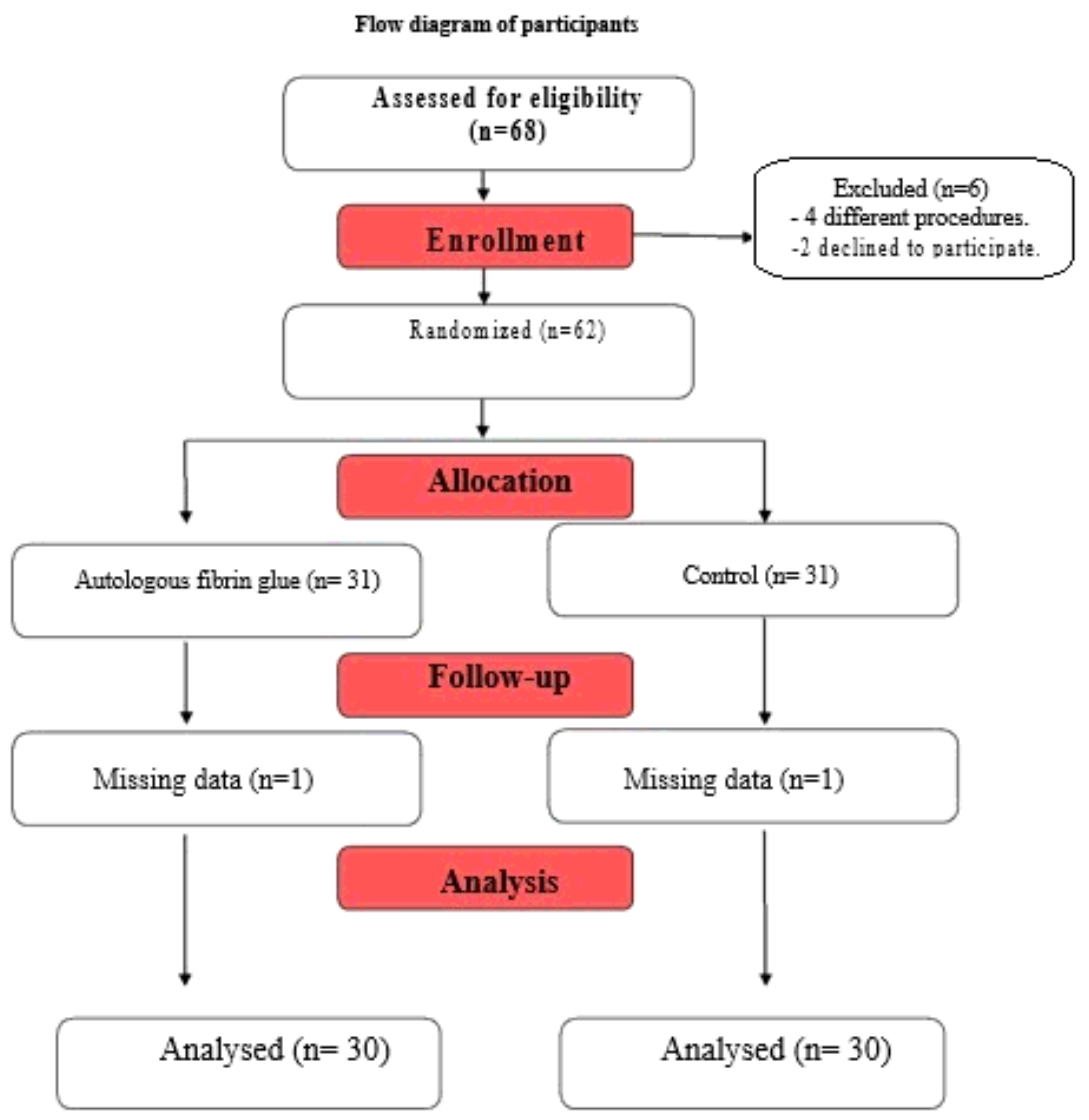

Figure 4

Flow Chart

\section{Supplementary Files}

This is a list of supplementary files associated with this preprint. Click to download.

- CONSORT2010checklist.doc 